\title{
Catalyses by Polymer Complexes. V. The Heterotropic (Allosteric) Interaction of Histamine- and Hydroxamate-Containing Polymer Catalysts with Hydrophobic Ammonium Salts in the Hydrolysis of Phenyl Esters*
}

\author{
Seiji Shinkai, Kunio Tou, and Toyoki Kunitake \\ Department of Organic Synthesis, Faculty of Engineering, \\ Kyushu University, Fukuoka 812, Japan.
}

(Received February 21, 1977)

\begin{abstract}
Three nucleophilic copolymers, $(N$-methacryloylhistamine--methacrylic acid (MHistm-MAc), $N$-methacryloylhistamine-methacrylamide (MHistm-MAm), and methacrylohydroxamic acid-methacrylic acid (MHAc-MAc)) were synthesized, and their hydrolytic reactivities toward $p$-nitrophenyl acetate (PNPA) and $p$-nitrophenyl hexanoate (PNPH) were studied in the absence and the presence of hydrophobic ammonium salts. The nucleophilic reactivity of MHistm-MAc toward PNPA was hardly affected by the addition of hydrophobic ammonium ions, while a marked increase of rates was found in the reaction with PNPH. Addition of these ammonium ions to the MHAc-MAc system enhanced the rate of the reaction with PNPH. This was produced by a $\mathrm{p} K_{\mathrm{a}}$ lowering $(0.3-0.4 \mathrm{p} K$ unit) and by the increase in the second-order rate constant (ca. 3 fold), as inferred from the $\mathrm{pH}$-rate profile. The rate-enhancing effect of the hydrophobic ammonium salts was analyzed by using the Hill equation which has been employed for analyzing the allosteric behavior in the enzyme system. The observed coefficient $(n=3 \sim 4)$ suggests that polymer-bound ammonium ions facilitate the subsequent binding considerably.
\end{abstract}

KEY WORDS Hydrophobic Ion Pair / Polyion Complex / Hydrolysis / Polymeric Hydroxamic Acid / Polymeric Histamine / Heterotropic (Allosteric) Interaction /

We showed recently that anionic nucleophiles were activated in the presence of a variety of cationic hydrophobic aggregates in aqueous systems. ${ }^{1-6}$ These rate enhancements can be attributed to the formation of "hydrophobic ion pair" between anionic nucleophiles and hydrophobic ammonium compounds. ${ }^{1-3}$ It should be interesting to extend this concept to polyion systems, since polyanions and polycations are known to form very stable complexes owing to the coulombic and hydrophobic interactions. ${ }^{7,8}$

We thus prepared the following water-soluble copolymers and assessed the influence of positively charged, hydrophobic additives on the nucleophilic reactivity of the imidazole, and hydroxamate functions toward $p$-nitrophenyl

\footnotetext{
* Contribution No. 414 from this department.
}

esters.

\section{EXPERIMENTAL}

\section{Materials}

$p$-Nitrophenyl methacrylate was prepared from an equimolar mixture of methacrylyl chloride and $p$-nitrophenol in an ice bath in the presence of excess pyridine. A small amount of hydroquinone was added to suppress polymerization. The reaction mixture was poured into water, and the phenyl ester produced was extracted with ether. The ether layer was washed with aqueous $0.5-N \mathrm{HCl}$ solution and water, and dried over calcium chloride. The solvent was evaporated in vacuo, and recrystallization of the yellow residue gave colorless needles; yield 50\%, $\mathrm{mp} 94.6-95.8^{\circ} \mathrm{C}$ (lit. $.^{9} 94.5-95.5^{\circ} \mathrm{C}$ ). 
S. Shinkai, K. Tou, and T. Kunitake

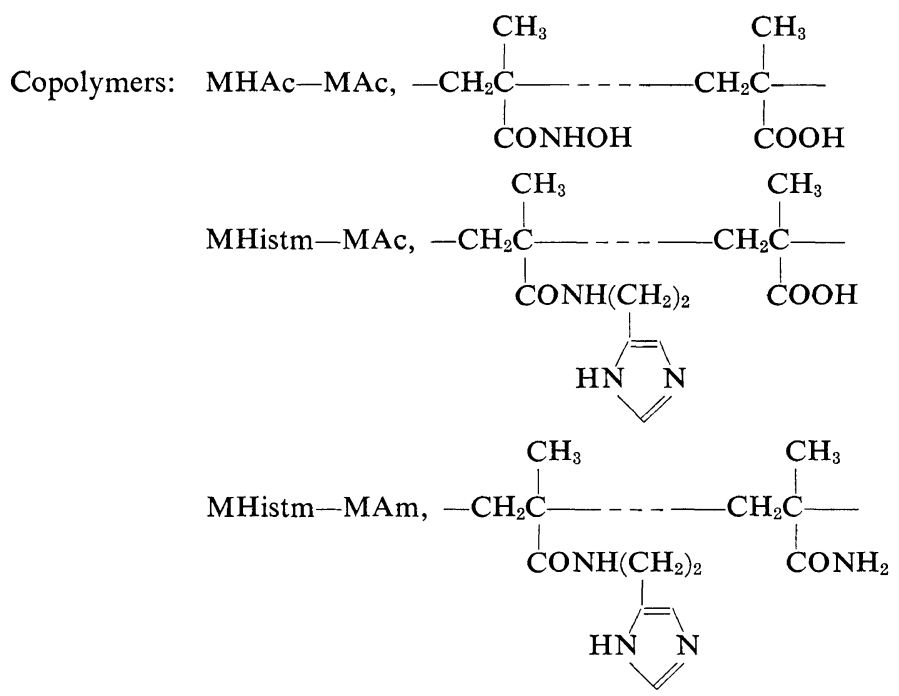

$\begin{array}{ll}\text { Additives: } & \mathrm{CTAB}, \mathrm{CH}_{3}\left(\mathrm{CH}_{2}\right)_{15} \stackrel{+}{\mathrm{N}}\left(\mathrm{CH}_{3}\right)_{3} \mathrm{Br}^{-} \\ & \text {TMAC, }\left[\mathrm{CH}_{3}\left(\mathrm{CH}_{2}\right)_{7}\right]_{3} \stackrel{+}{\mathrm{N}} \mathrm{CH}_{3} \mathrm{Cl}^{-} \\ & (\mathrm{N}-\mathrm{R})_{4},\left(\mathrm{CH}_{3}\right)_{2} \stackrel{+}{\mathrm{N}}-\left[\mathrm{CH}_{2} \mathrm{CH}_{2} \stackrel{+}{\mathrm{N}}\left(\mathrm{CH}_{3}\right)\right]_{3}-\mathrm{CH}_{3} \mathrm{Br}_{4}- \\ & \stackrel{\mid}{\mathrm{R}}\end{array}$

$\mathrm{R}: \mathrm{Me}=$ methyl, $\mathrm{Bzl}=$ benzyl, Oct $=$ octyl, Dod $=$ dodecyl, Octde $=$ octadecyl.

SDS, $\mathrm{CH}_{3}\left(\mathrm{CH}_{2}\right)_{11} \mathrm{OSO}_{3} \mathrm{Na}$

Brij-35, $\mathrm{CH}_{3}\left(\mathrm{CH}_{2}\right)_{11}\left(\mathrm{OCH}_{2} \mathrm{CH}_{2}\right)_{23} \mathrm{OH}$

POOA, $\mathrm{CH}_{3}\left(\mathrm{CH}_{2}\right)_{7} \mathrm{CH}=\mathrm{CH}\left(\mathrm{CH}_{2}\right)_{7} \mathrm{CH}_{2}\left(\mathrm{OCH}_{2} \mathrm{CH}_{2}\right)_{10} \mathrm{OH}$

Substrates:

$\mathrm{PNPA}, \mathrm{CH}_{3} \mathrm{COO}-\left\langle-\mathrm{NO}_{2}\right.$

$\mathrm{PNPH}, \mathrm{CH}_{3}\left(\mathrm{CH}_{2}\right)_{4} \mathrm{COO}-\ll-\mathrm{NO}_{2}$

$m$ - $N, N$-Dimethylaminophenyl methacrylate was similarly prepared by reaction of an equimolar mixture of methacryloyl chloride and $m-N, N$ dimethylaminophenol in an ice bath in the presence of aqueous 5-\% NaOH; yield $81 \%$, bp $83-85^{\circ} \mathrm{C} / 0.07 \mathrm{mmHg}$. Anal. Found: C, 69.91; $\mathrm{H}, 7.31 ; \mathrm{N}, 6.68$. Calcd for $\mathrm{C}_{12} \mathrm{H}_{15} \mathrm{NO}_{2}: \mathrm{C}, 70.21$, $\mathrm{H}, 7.37 ; \mathrm{N}, 6.82$.

Hexadecyltrimethylammonium bromide (CTAB), trioctylmethylammonium chloride (TMAC), and sodium dodecyl sulfate (SDS) are products of Wako Pure Chem. Ind. Polyoxyethylene $(n=10)$ oleyl alcohol and Brij-35 were purchased from Tokyo Kasei. CTAB was recrystallized from ethanol before use, while other surfactants were used without further purification. Tetra- alkylated triethylenetetamines were prepared and characterized by Hirotsu $^{10}$ and Okahata, et al. ${ }^{11}$ Preparations of $p$-nitrophenyl acetate (PNPA, $\mathrm{mp} 83.5-84.5^{\circ} \mathrm{C}$ ) and $p$-nitrophenyl hexanoate (PNPH, bp $142-147^{\circ} \mathrm{C} / 0.2 \mathrm{mmHg}$ ) have been described previously. ${ }^{12}$

\section{Polymerization and Polymer Reaction}

Polymerizations were carried out in benzene using azobisisobutyronitrile (1-3\% of monomer) as the initiator at $70^{\circ} \mathrm{C}$. $\quad \operatorname{Poly}(p$-nitrophenyl methacrylate) was recovered by pouring into ether (yield $85-90 \%)$, and poly $(m-N, N$-dimethylaminophenyl methacrylate) was recovered by pouring into methanol (yield 97\%). The polymer catalysts were prepared from these polymers according to the following schemes. 
Catalyses by Polymer Complexes. V.
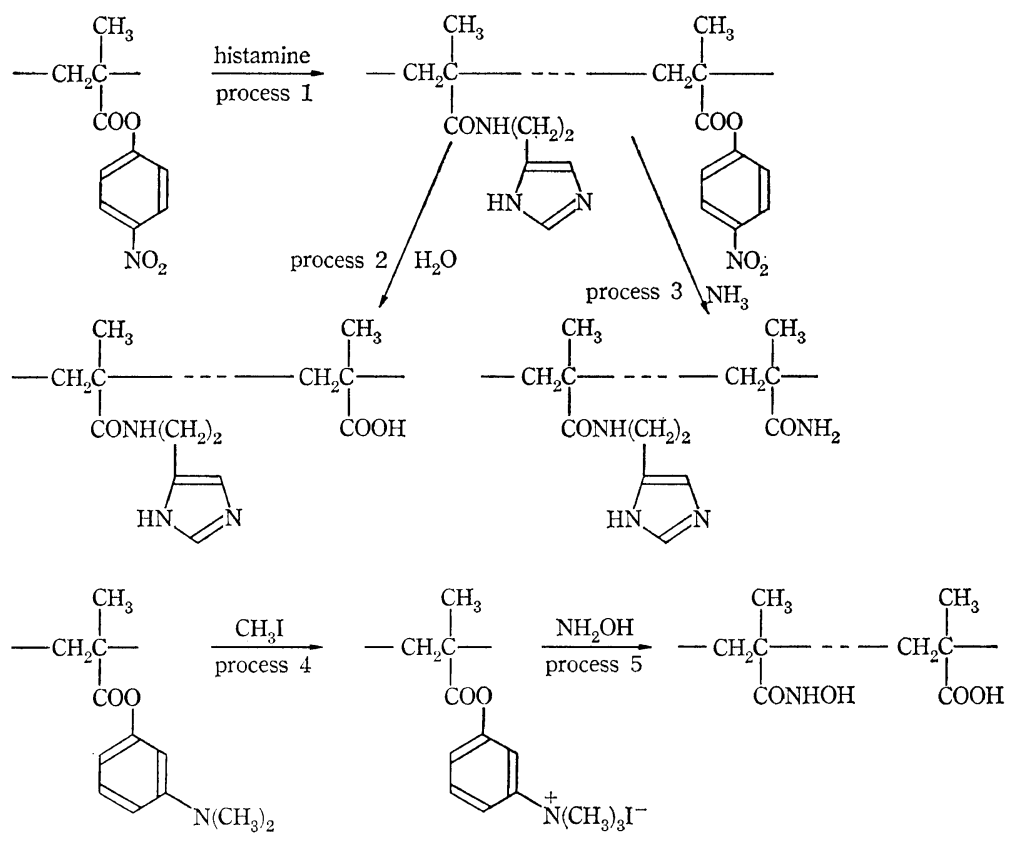

Process 1: $6.67 \mathrm{~g}(30 \mathrm{mmol})$ of poly ( $p$-nitrophenyl methacrylate), $2.76 \mathrm{~g}(15 \mathrm{mmol})$ of histamine dihydrochloride, and $4.5 \mathrm{ml}$ of triethylamine were dissolved in $70 \mathrm{ml}$ of dimethylformamide, and heated at $90-100^{\circ} \mathrm{C}$ for $24 \mathrm{hr}$. Precipitates $\left(\mathrm{Et}_{3} \mathrm{~N} \cdot \mathrm{HCl}\right)$ were filtered and the solusion was poured into ether; recovered polymer, $8.4 \mathrm{~g}$.

Process 2: $2 \mathrm{~g}$ of the histamine-containing polymer were dissolved in aqueous $1-N \mathrm{NaOH}$ solution, and heated at $40^{\circ} \mathrm{C}$ for $24 \mathrm{hr}$. The polymer solution was subjected to extensive dialysis until the yellow color of $p$-nitrophenolate disappeared. The IR spectrum of the polymer recovered by pouring into tetrahydrofuran showed an amide absorption $\left(1650 \mathrm{~cm}^{-1}\right)$ instead of an ester absorption $\left(1750 \mathrm{~cm}^{-1}\right)$. The composition of the polymer (MHistm-MAc) was determined by titrating the MHistm unit (Table I).

Process 3: $2 \mathrm{~g}$ of the histamine-containing polymer were dissolved in $20 \mathrm{ml}$ of dimethylformamide, and dry ammonia gas was introduced. A small amount of imidazole was added, in order to promote the aminolysis. The reaction was continued for $24 \mathrm{hr}$ at room temperature. The polymer was recovered by pouring into acetone, and was further purified by reprecipitation from water and acetone. The IR
Table I. Composition of polymer calalysts

\begin{tabular}{lccrc}
\hline \multicolumn{1}{c}{ Polymer } & $\begin{array}{c}\text { MHistm } \\
\text { mol\% }\end{array}$ & $\begin{array}{c}\text { MHAc, } \\
\text { mol\% }\end{array}$ & $\mathrm{p} K_{\mathrm{a}}$ & $n^{\prime}$ \\
\hline MHistm-MAc $^{\mathrm{a}}$ & 18 & - & 7.25 & - \\
MHistm-MAm $^{\mathrm{a}}$ & 20 & - & 6.20 & 3.17 \\
MHAc-MAc & - & $19^{\mathrm{b}}$ & $10.4^{\mathrm{c}}$ & 0.94 \\
\hline
\end{tabular}

a Determined by titration at $30^{\circ} \mathrm{C}, \mu=1.0$ with $\mathrm{KCl} . \mathrm{p} K_{\mathrm{a}}$ denotes the half-neutralized $(\alpha=0.5)$ $\mathrm{pH}$ value. $\mathrm{p} K_{\text {int }}$ for $\mathrm{MHistm}-\mathrm{MAm}=6.79 . \quad n^{\prime}=$ $\left(\mathrm{p} K_{\mathrm{a}}-\mathrm{pH}\right) / \log [(1-\alpha) / \alpha] . \quad n^{\prime}$ value for MHistmMAc could not be determined because of insufficient separation of the titration curve.

b Determined by elemental analysis.

c Determined kinetically (see Results section).

spectrum of the resultant polymer showed no ester absorption around $1750 \mathrm{~cm}^{-1}$. The polymer composition was determined by titrating the MHistm unit (Table I).

Process 4: $9.4 \mathrm{~g}(49 \mathrm{mmol})$ of $\operatorname{poly}(m-N, N$ dimethylaminophenyl methacrylate) were dissolved in $60 \mathrm{~m} l$ of dimethylformamide, and $25 \mathrm{~g}$ $(176 \mathrm{mmol})$ of methyl iodide were added. The reaction mixture was stirred at room temperature for $2.5 \mathrm{hr}$, and $10 \mathrm{~g}(52 \mathrm{mmol})$ of methyl iodide were again added. The polymer war recovered by pouring into acetone, and 


\section{S. Shinkai, K. Tou, and T. Kunitake}

reprecipitated from dimethylformamide and ether-acetone $(1: 1)$. Anal. Found: C, 43.06; $\mathrm{H}, 5.44 ; \mathrm{N}, 3.98$. Calcd for $\mathrm{C}_{13} \mathrm{H}_{18} \mathrm{NO}_{2} \mathrm{I}: \mathrm{C}$, 44.97; H, 5.22; N, 4.03.

Process 5: $3.47 \mathrm{~g}(1 \mathrm{mmol})$ of poly $(m$-methacryloyloxy $N, N, N$-trimethylanilinium iodide and $1 \mathrm{~g}(3 \mathrm{mmol})$ of hydroxylamine which had been freed by excess triethylamine were dissolved in $30 \mathrm{ml}$ of dimethylformamide, and heated at $80^{\circ} \mathrm{C}$ for $24 \mathrm{hr}$. The solvent was evaporated in vacuo, and the residue was taken in methanol. The polymer was recovered by pouring into aqueous $0.01-N \mathrm{HCl}$ solution. The IR spectrum showed two carbonyl absorptions at $1710 \mathrm{~cm}^{-1}$ $(-\mathrm{COOH})$ and $1670 \mathrm{~cm}^{-1}$ (- $\left.\mathrm{CONH}-\right)$. The polymer composition was determined by elemental analysis (Table I).

\section{Rate Measurements}

The hydrolytic rate of $p$-nitrophenyl esters was determined at $30^{\circ} \mathrm{C}$ by following the increase in the absorption of $p$-nitrophenolate anion at $401 \mathrm{~nm}$. In all cases, excess polymer catalysts (i.e., excess MHistm and MHAc units) were present, so that pseudo first-order kinetics were observed. From the pseudo first-order rate constant ( $=k_{\text {total }}-k_{\mathrm{H}_{2} \mathrm{O}}: k_{\mathrm{H}_{2} \mathrm{O}}$, the rate of spontaneous decay) thus obtained, the apparent second-order rate constant $\left(k_{\text {obsd }}\right)$ was calculated. The reactions of MHistm-MAc and MHistmMAm with PNPA were carried out mainly at $\mathrm{pH} 9.1$ (0.02- $M$ borate buffer), where the imidazole group is mostly dissociated ( $\mathrm{p} K_{\mathrm{a}}$ of MHistm 6-7; Table I). Therefore, $k_{\text {obsd }}$ is equal to the true second-order rate constant $\left(k_{\mathrm{a}}\right)$. The reaction of MHAc-MAc was carried out mainly at $\mathrm{pH} 10.0(0.02-M$ carbonate buffer), and the true second-order constant $\left(k_{\mathrm{a}}\right)$ was evaluated from the $\mathrm{pH}-$ rate profile (Figure 5).

\section{RESULTS}

Catalytic Hydrolysis with the Imidazole-Containing Copolymer

First, the rates of the spontaneous decay of PNPA and PNPH substrates $\left(k_{\mathrm{H}_{2}} \mathrm{O}\right)$ were eva- luated under various reaction conditions. The results are summarized in Table II. Additives did not affect very much the spontaneous decay although the hydrolysis was somewhat faster in the presence of $(\mathrm{N} \text {-Octde })_{4}$.

The effect of added ammonium salts on the catalytic hydrolysis of PNPA with MHistm-MAc (eq 1) is illustrated in Figure 1.

Table II. Spontaneous hydrolysis of PNPA and $\mathrm{PNPH}^{\mathrm{a}}$

\begin{tabular}{|c|c|c|c|c|}
\hline Substrate & Reaction & medium & $\mathrm{pH}$ & $\underset{\mathrm{sec}^{-1}}{k_{\mathrm{H}_{2} \mathrm{O}} \times 10^{4}}$ \\
\hline \multirow[t]{7}{*}{ PNPA } & \multicolumn{2}{|l|}{ None } & 9.10 & 3.55 \\
\hline & CTAB & $0.1 \mathrm{~m} M$ & 9.10 & 3.53 \\
\hline & $\left\{\begin{array}{l}\text { CTAB } \\
\text { poly }(\mathrm{MAc})\end{array}\right.$ & $0.1 \mathrm{~m} M$ & \multirow[t]{2}{*}{9.10} & \multirow[t]{2}{*}{3.48} \\
\hline & $(N \text {-Octde })_{4}$ & $\begin{array}{l}2.5 \mathrm{~m} M \\
0.1 \mathrm{~m} M\end{array}$ & & \\
\hline & $\left\{\begin{array}{l}\text { poly (MAc) } \\
\text { (a) }\end{array}\right.$ & $2.5 \mathrm{~m} M$ & 9.10 & 4.80 \\
\hline & $\int(N-\mathrm{Bzl})_{4}$ & $0.5 \mathrm{mM}$ & \multirow{2}{*}{9.24} & \multirow{2}{*}{5.40} \\
\hline & $\{$ poly(MAc) & $2.5 \mathrm{mM}$ & & \\
\hline \multirow[t]{6}{*}{ PNPH } & None & & 9.15 & 2.29 \\
\hline & poly(MAc) & $2.5 \mathrm{~m} M$ & 9.15 & 2.25 \\
\hline & СТAB & $0.1 \mathrm{~m} M$ & \multirow{2}{*}{9.10} & \multirow{2}{*}{2.05} \\
\hline & (poly(MAc) & $2.5 \mathrm{mM}$ & & \\
\hline & $\left\{(N \text {-Octde })_{4}\right.$ & $0.1 \mathrm{~m} M$ & \multirow[t]{2}{*}{9.13} & \multirow{2}{*}{3.01} \\
\hline & (poly(MAc) & $2.5 \mathrm{~m} M$ & & \\
\hline
\end{tabular}

a $30^{\circ} \mathrm{C}, \mu=0.02$ with $\mathrm{KCl}, 3$ vol-\% ethanol.

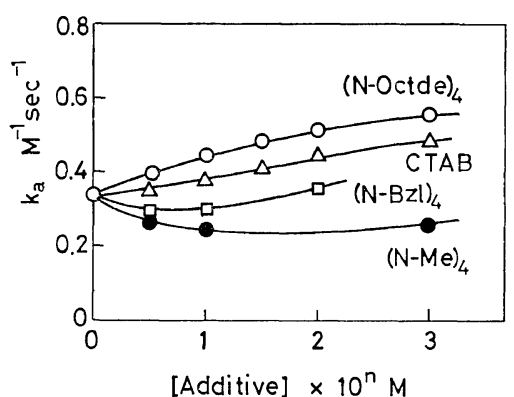

Figure 1. Second-order rate constants for the reaction of MHistm-MAc and PNPA plotted against the concentration of added ammonium salts: $\mathrm{pH}$ $9.10 \pm 0.03,3$ vol $\%$ ethanol; $\mu=0.01$ with $\mathrm{KCl}$; $[$ MHistm unit $]=4.23 \times 10^{-4} M ;[\mathrm{PNPA}]=4.36 \times 10^{-5}$ $M ; n=3$ for $\left(N-\mathrm{Bzl}_{4}\right.$ and $(N-\mathrm{Me})_{4} ; n=4$ for $(N$ Octde $)_{4}$ and CTAB.

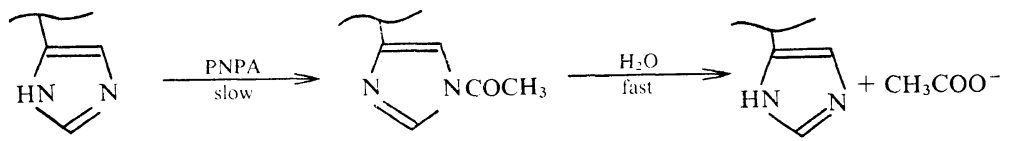


Catalyses by Polymer Complexes. V.

The addition of $(N-\mathrm{Me})_{4}$ slightly retarded the hydrolytic rate, while $(N-\mathrm{Bzl})_{4}$ had a very small effect. On the other hand, CTAB and $(\mathrm{N} \text {-Octde })_{4}$ produced rate enhancements. The concentration of added CTAB is below its critical micelle concentration $(\mathrm{cmc})$ under kinetic conditions.* The cmc of $(N \text {-Octade })_{4}$, if present, is said to be below $5 \times 10^{-5} M .^{11}$ These rate augmentations were only $1.4-1.6$ fold.

More distinct rate enhancements were observed by employing PNPH, which is a more hydrophobic substrate. As shown in Figure 2, $(N$ $\mathrm{Bzl}_{4}$ was only slightly effective. In contrast, CTAB and TMAC (typical phase-transfer catalysts) readily produced rate augmentations of 20-40 fold, and the rate increased with an increase in the concentration of these ammonium salts. Apparently, the hydrophobicity around the polymer chain was strengthened by the binding of hydrophobic ammonium ions (CTAB

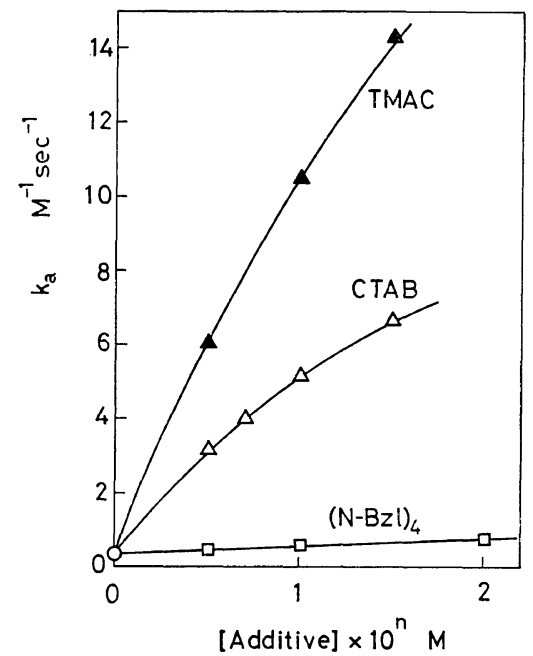

Figure 2. Second-order rate constants for the reaction of MHistm-MAc and PNPH plotted against the concentration of added ammonium salts. $[\mathrm{PNPH}]=4.54 \times 10^{-5} M$. Other reaction conditions are recorded under Figure 1: $n=3$ for $(N$ $\mathrm{Bzl})_{4} ; n=4$ for TMAC and CTAB.

* The cmc of CTAB determined with dichlorophenolindophenol at $30^{\circ} \mathrm{C}, 3$ vol- $\%$ ethanol was: $8.0 \times$ $10^{-4} M$ at $\mu=0.01$ and $3.8 \times 10^{-4} M$ at $\mu=0.06$. Therefore, the micelle would not be formed under kinetic conditions, except at the relatively high concentrations in Figure 4.

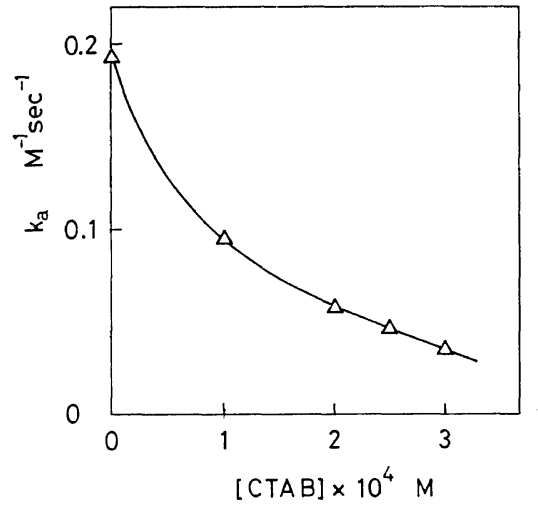

Figure 3. Second-order rate constants for the reaction of MHistm-MAm and PNPH plotted against the concentration of CTAB: $\mathrm{pH} 9.00 \pm 0.03,3$ vol- $\%$ ethanol; $\mu=0.01$ with $\mathrm{KCl}$; [MHistm $]=4.50 \times 10^{-4} M$; $[\mathrm{PNPH}]=4.54 \times 10^{-5} \mathrm{M}$.

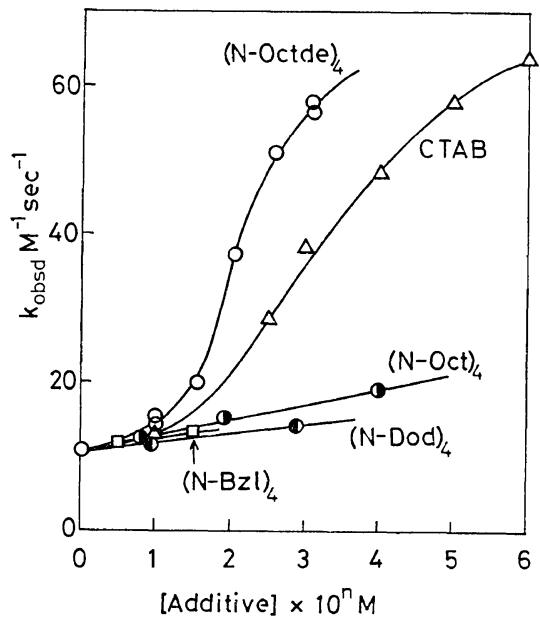

Figure 4. Apparent second-order rate constants at $\mathrm{pH} 10.00 \pm 0.03$ for the reaction of MHAc-MAc and PNPA plotted against the concentration of added ammonium salts: 3 vol- $\%$ ethanol, $\mu=0.06$ with $\mathrm{KCl}$; $[\mathrm{MHAc}]=2.01 \times 10^{-4} M$; $[\mathrm{PNPA}]=2.05$ $\times 10^{-5} M ; n=3$ for $(N-\mathrm{Bzl})_{4} ; n=4$ for $(N \text {-Octde })_{4}$, $(N \text {-Dod })_{4},(N \text {-Oct })_{4}$, and CTAB.

and TMAC) and the rate increase was due to concentration of hydrophobic PNPH.

The addition of anionic (SDS $0.3 \mathrm{mM}$ ) and nonionic (Brij-35, 0.3 $\mathrm{mM}$ ) surfactants were found to be ineffective.

In the catalytic hydrolysis of PNPH with MHistm-MAm, the addition of CTAB lowered 
the reaction rate as shown in Figure 3. This result contrasts well with those observed for MHistm-MAc catalyst.

Catalytic Hydrolysis with the MHAc-MAc Copolymer

It is known that the acylation of the hydro- xamate anion takes place fast, while the deacylation is relatively slow. ${ }^{14-16}$ Therefore, the $k_{\text {obsd }}$ value with MHAc-MAc copolymer under the pseudo first-order condition is equivalent to the acyl-transfer rate from PNPA to the MHAc unit (eq 2).

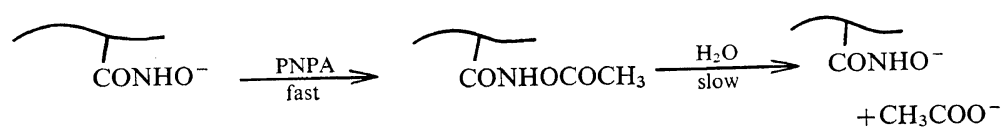

Figure 4 shows the apparent second-order rate constant $\left(k_{\text {obsd }}\right)$ for the reaction of MHAc-MAc and PNPA and $\mathrm{pH} 10.0$ plotted against the concentration of added ammonium salts. As expected, the addition of $(N-\mathrm{Bzl})_{4}$ and $(N-\mathrm{Me})_{4}$ was not very effective. The more hydrophobic CTAB and $(N \text {-Octde })_{4}$ produced rate enhancements by 6-7 times. The addition of anionic (SDS) and nonionic (POOA) surfactants decelerated the reaction (see Table III).

$p H$ Dependence of the Reaction of $M H A c-M A c$ and PNPA

The $\mathrm{pH}$ dependence of the rate for the reaction of MHAc-MAc and PNPA was studied in the presence and the absence of ammonium salts (Figure 5). The apparent second-order rate constant, $k_{\text {obsd }}$ is easily afforded by eq 3 , where $\alpha$ is the dissociated fraction of MHAc units. In the polymeric system, however, $\alpha$ should be related to $\mathrm{pH}$ through the modified HendersonHasselbach equation (eq 4 ), ${ }^{17}$ so that $\alpha$ is expressed by eq 5 .

Table III. Catalytic hydrolysis of PNPA with MHAc-MAc ${ }^{a}$

\begin{tabular}{|c|c|c|c|c|c|}
\hline \multicolumn{2}{|l|}{ Additive } & \multirow{2}{*}{$\begin{array}{c}k_{\text {obsd }} \text { at } \\
\mathrm{pH} 10.0 \\
M^{-1} \mathrm{sec}^{-1}\end{array}$} & \multirow{2}{*}{$\begin{array}{c}k_{\mathrm{a}} \\
M^{-1} \sec ^{-1}\end{array}$} & \multirow{2}{*}{$\mathrm{p} K$} & \multirow{2}{*}{$n^{\prime}$} \\
\hline & $\mathrm{m} M$ & & & & \\
\hline None & & 10.7 & 32 & 10.4 & 0.94 \\
\hline CTAB & 0.30 & 38.3 & 85 & 10.1 & 1.03 \\
\hline$(N \text {-Octde })_{4}$ & 0.30 & 57.7 & 93 & 10.0 & 0.92 \\
\hline$(N \text {-Dod })_{4}$ & 0.29 & 13.9 & & & \\
\hline$(N-\mathrm{Oct})_{4}$ & 0.20 & 15.5 & & & \\
\hline$\left(N-\mathrm{Bzl}_{4}\right.$ & 1.50 & 13.3 & & & \\
\hline SDS & 0.44 & 7.4 & & & \\
\hline POOA & 1.0 & 4.8 & & & \\
\hline
\end{tabular}

a $30^{\circ} \mathrm{C}, \mu=0.06$ with $\mathrm{KCl}, 3$ vol- $\%$ ethanol, $\mathrm{pH}$ $10.0 \pm 0.03$ with $0.02 M$ carbonate.

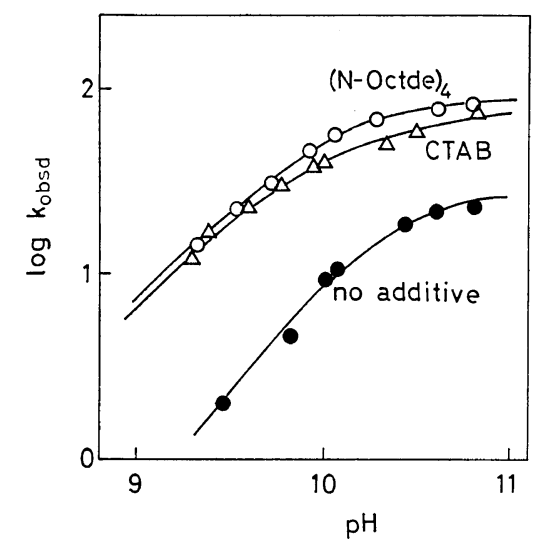

Figure 5. $\mathrm{pH}$ dependence for the reaction of MHAc-MAc and PNPA: [ $(N \text {-Octde })_{4}=3.08 \times 10^{-4}$ $M ;[\mathrm{CTAB}]=3.00 \times 10^{-4} M$. Ammonium salt was not added where the circles are filled.

$$
\begin{gathered}
k_{\mathrm{obsd}}=k_{\mathrm{a}} \alpha \\
\mathrm{pH}=\mathrm{p} K_{\mathrm{a}}-n^{\prime} \log [(1-\alpha) / \alpha] \\
\alpha=\frac{1}{\left(a_{\mathrm{H}} / K_{\mathrm{a}}\right)^{1 / n^{\prime}}+1}
\end{gathered}
$$

From eq 3 and 4 , eq 6 follows.

$$
\log \left(\frac{k_{\mathrm{a}}}{k_{\text {obsd }}}-1\right)=\frac{1}{n^{\prime}}\left(\mathrm{p} K_{\mathrm{a}}-\mathrm{pH}\right)
$$

Equation 6 shows that, if the $k_{\mathrm{a}}$ value is determined separately, then $n^{\prime}$ and $\mathrm{p} K_{\mathrm{a}}$ are calculated from a linear relation of $\mathrm{pH}$ and $\log \left[\left(k_{\mathrm{a}} / k_{\mathrm{obsd}}\right)-\right.$ 1]. $k_{\mathrm{a}}$ values were evaluated by extrapolating the curves in Figure 5 to higher $\mathrm{pH}$ values. Thus, the $k_{\mathrm{a}}$ values listed in Table III were obtained. As illustrated in Figure 6, plots of $\mathrm{pH}$ vs. $\log \left[\left(k_{\mathrm{a}} / k_{\mathrm{obsd}}\right)-1\right]$ provided straight lines $(r>$ 0.99 ), from which $n^{\prime}$ and $\mathrm{p} K_{\mathrm{a}}$ values were determined by the least squares method. As given 


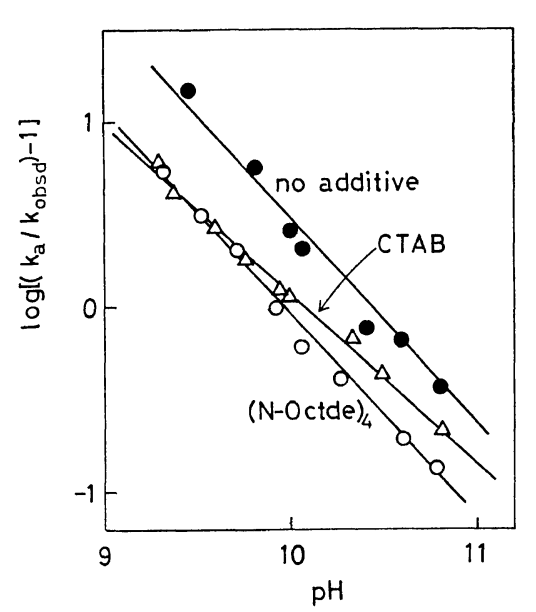

Figure 6. $\mathrm{pH}$ vs. $\log \left[\left(k_{\mathrm{a}} / k_{\mathrm{obsd}}\right)-1\right]$. Ammonium salt was not added for filled circles.

in Table III, $n^{\prime}$ values are close to unity, and $\mathrm{p} K_{\mathrm{a}}$ values are lowered by the $0.3-0.4 \mathrm{p} K_{\mathrm{a}}$ unit in the presence of CTAB and $(N \text {-Octde })_{4}$. The second-order rate constants $\left(k_{\mathrm{a}}\right)$ are enhanced by ca. 3 fold by the addition of CTAB and $\left(N^{\prime}\right.$ Octade $)_{4}$.

\section{DISCUSSION}

As shown in Figure 1, the reaction of PNPA and MHistm-MAc was affected little by addition of hydrophobic ammonium salts. On the other hand, the hydrolytic rate of PNPH by the same polymer was influenced to a greater extent (Figures 2 and 3). Thus, the change of the microenvironment of the polymer domain due to binding of hydrophobic ammonium ions is reflected by the hydrolysis of PNPH more sensitively than by the hydrolysis of PNPA. This difference is probably attributed to the greater hydrophobicity of the former substrate.

It is interesting that the influence of hydrophobic ammonium ions in the PNPH hydrolysis is reversed with these two polymer catalysts: rate acceleration for anionic MHistm-MAc copolymer and rate depression for neutral MHistm-MAm copolymer. The ammonium ions are bound to MHistm-MAc polymer by coulombic and hydrophobic interactions, and the resulting polymer complex is neutral or negative. However, binding of the ammo- nium ions to neutral MHistm-MAm should be hydrophobic in nature and cause the resulting polymer complex to be positively-charged. Therefore, these polymer complexes should provide different microenvironments for the reaction of the imidazole function with PNPH. It is not yet clear why hydrophobic ammonium ions caused rate enhancements with one polymer catalyst and rate depression with the other polymer catalyst.

The hydroxamate anion in nonionic micelles is markedly activated upon addition of hydrophobic ammonium salts such as CTAB and TMAC. $^{2,3}$ This is conceivably caused by the formation of ion pairs between hydroxamate anions and added ammonium ions, and, in fact, the relation between the reaction rate and the ammonium concentration was a simple saturation type. ${ }^{3}$

The polymeric hydroxamate (MHAc-MAc) is also activated in the hydrolysis of PNPA by the addition of hydrophobic ammonium salts (Figure 4), although the extent of activation is much smaller than reported previously. ${ }^{4,12,18,19}$ It is remarkable that the rate increase is sigmoidal rather than characteristic of the simple saturation type (vide supra). Sigmoidal curves have been observed for the association of anionic surfactants with certain water-soluble polymers such as poly(ethylene oxide), poly(vinyl alcohol), and poly( $N$-vinylpyrrolidone). ${ }^{20-22}$ These results were interpreted as follows: the hydrophobicity of these water-soluble polymers is relatively small, and so complexation is not very large at low concentrations of the surfactant. However, once complexation takes place, the hydrophobicity of the polymer is progressively strengthened and further complexation becomes easier. It is believed that PNPA is not significantly concentrated in the micellar phase of $\mathrm{CTAB}^{23}$ and polysoaps. ${ }^{4,24,25}$ Therefore, the observed rate enhancement may be ascribed to the catalytic activation of the hydroxamate polymer (MHAcMAc). The activation can be caused generally by lowering the $\mathrm{p} K_{\mathrm{a}}$ (increase in the anion fraction) and/or by the activation of a given anionic nucleophile $\left(k_{\mathrm{a}}\right.$ term). ${ }^{26}$ In the present case, it is seen from Table III that both terms $\left(\mathrm{p} K_{\mathrm{a}}\right.$ and $k_{\mathrm{a}}$ ) contributed to the increase in the observed rate $\left(k_{\mathrm{obsd}}\right)$ of Figure 4. 
In an attempt to analyze the sigmoidal profile quantitatively, we assumed that Scheme I applies

$$
\begin{aligned}
& \mathrm{MHAc}+n \mathrm{~A} \stackrel{K}{\rightleftarrows} \mathrm{MHAc} \cdot \mathrm{A}_{n} \\
& \underset{\text { product }}{\downarrow} k_{\text {obsd }}^{\prime} \text { [PNPA] } \underset{\text { product }}{\downarrow} k_{\text {obsd }}^{\prime \prime}[\mathrm{PNPA}]
\end{aligned}
$$

\section{Scheme I}

where $k_{\mathrm{obsd}}^{\prime}$ and $k_{\mathrm{obsd}}^{\prime \prime}$ denote the apparent secondorder rate constant for the uncomplexed polymer and that for the polymer complexed with additive A, respectively. $K$ is the association constant defined as $K=\left[\mathrm{MHAc} \cdot \mathrm{A}_{n}\right] /[\mathrm{MHAc}][\mathrm{A}]^{n}$. It should be noted that $K$ is also a function of the dissociation of the hydroxamic acid. Modification of the equation derived by Connors, et al. ${ }^{27}$ gives eq 7

$$
\frac{k_{\mathrm{obsd}}^{\prime}}{k_{\mathrm{obsd}}-k_{\mathrm{obsd}}^{\prime}}=\frac{1}{q K[\mathrm{~A}]^{n}}+\frac{1}{q}
$$

where $q=\left(k_{\mathrm{obsd}}^{\prime \prime} / k_{\mathrm{obsd}}^{\prime}\right)-1$. Equation 7 can be rewritten as eq 8 or 9 . Thus, if $k_{\text {obsd }}^{\prime \prime}$ can be determined independently, plots of $\log \left[k_{\mathrm{obsd}}^{\prime} /\right.$ $\left.\left(k_{\text {obsd }}-k_{\text {obsd }}^{\prime}\right)-1 / q\right]$ vs. $\log [\mathrm{A}]$ would give a linear relation.

$$
\log \left(\frac{k_{\mathrm{obsd}}^{\prime}}{k_{\mathrm{obsd}}-k_{\mathrm{obsd}}^{\prime}}-\frac{1}{q}\right)=-n \log [\mathrm{A}]-\log q K
$$

or

$$
\log \left(\frac{k_{\text {obsd }}-k_{\text {obsd }}^{\prime}}{k_{\text {obsd }}^{\prime \prime}-k_{\text {obsd }}}\right)=n \log [\mathrm{A}]+\log K
$$

Thus, determination of $k_{\text {obsd }}^{\prime \prime}$ values which would satisfy the relation of eq 8 was attempted by trial-and-error computation using the data of Figure 4. Figure 7 shows plots of eq 8 for $k_{\text {obsd }}^{\prime \prime}=$ $68 M^{-1} \mathrm{sec}^{-1}$ (CTAB) and $72 \mathrm{M}^{-1} \mathrm{sec}^{-1}((N$ Octde $\left.)_{4}\right)$. The correlation coefficients were better than 0.99. From the slope $(-n)$ and the intercept $(-\log q K), n$ and $K$ were obtained: for CTAB $n=3.0, K=3.6 \times 10^{10} M^{-n}$; for $(N \text {-Octde })_{4}$ $n=3.6, K=1.6 \times 10^{13} M^{-n}$.

The $n$ value in eq 8 may be equated to the coefficient in Hill's empirical equation. ${ }^{28} \mathrm{~A}$ positive homotropic behavior is seen when the enzyme binds the substrate cooperatively: binding of the substrate stimulate (or inhibits) the interaction with additional substrate(s). When this is caused by a compound other than a substrate (i.e., effector), the behavior is designated

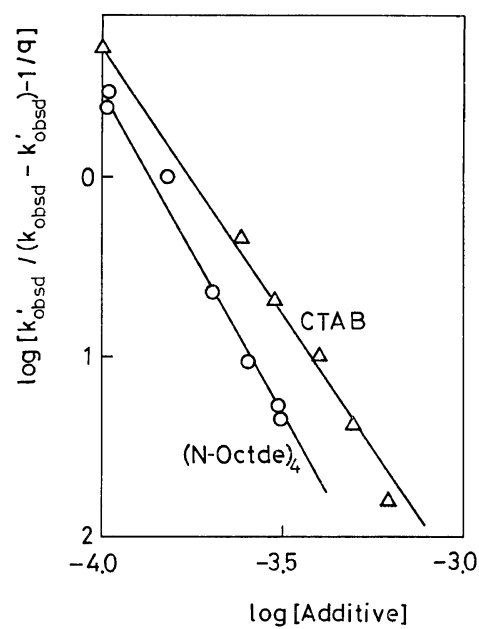

Figure 7. $\log$ [Additive] $v s . \log \left[k_{\text {obsd }}^{\prime} /\left(k_{\text {obsd }}-k_{\text {obsd }}^{\prime}\right)\right.$ $-1 / q]$.

as a positive heterotropic response. This phenomenon is known to play an important role in the regulation of the metabolism. ${ }^{29,30}$ Allosteric enzymes usually possess Hill's coefficients of $1.3-1.8 .^{30-33}$ Therefore, the positive heterotropic behavior observed in the present system is relatively large, indicating that polymer-bound ammonium ions facilitate subsequent binding considerably.*

Acknowledgment. The authors express their thanks to Dr. Y. Osada for helpful discussion.

\section{REFERENCES}

1. S. Shinkai and T. Kunitake, Chem. Lett., 109 (1976)

2. T. Kunitake, S. Shinkai, and Y. Okahata, Bull. Chem. Soc. Jpn., 49, 540 (1976) and references cited therein.

3. S. Shinkai and T. Kunitake, J. Chem. Soc., Perkin Trans. II, 980 (1976).

4. T. Kunitake, S. Shinkai, and S. Hirotsu, Biopolymers, 15, 1129 (1976).

5. S. Shinkai and T. Kunitake, Makromol. Chem., in press.

6. S. Shinkai and T. Kunitake, Bull. Chem. Soc. Jpn., 49, 3219 (1976).

* Recently, an attempt to apply the Hill's equation to micelle-catalyzed system was reported by Piszkiewicz, ${ }^{34}$ in which $n$ values of 1 to 5 were observed. 
Catalyses by Polymer Complexes. V.

7. E. Tsuchida and Y. Osada, Kobunshi (High Polymers, Jpn.), 22, 384 (1973).

8. E. Tsuchida and Y. Osada, Makromol. Chem., 175, 593 (1974).

9. H. Morawetz and P. E. Zimmering, J. Phys. Chem., 58, 753 (1959).

10. S. Hirotsu, Master Thesis, Faculty of Engineering, Kyushu University, 1976.

11. Y. Okahata, R. Ando, and T. Kunitake, Polymer Preprints, Jpn., 25, 53 (1976).

12. T. Kunitake, S. Shinaki, and S. Hirotsu, $J$. Polym. Sci., Polym. Lett. Ed., 13, 377 (1975).

13. E. J. Fendler and J.H. Fendler, Adv. Phys. Chem., 8, 271 (1970).

14. S. L. Johnson, ibid., 5, 237 (1967).

15. T. Kunitake, Y. Okahata, and R. Ando, Bull. Chem. Soc. Jpn., 47, 1509 (1974).

16. S. Shinkai and T. Kunitake, Polym. J., 7, 387 (1975).

17. A. Katchalsky and P. Spitnik, J. Polym. Sci., 2, 432 (1947).

18. I. Tabushi, Y. Kuroda, and S. Kita, Tetrahedron Lett., 643 (1974).

19. T. Kunitake, Y. Okahata, and T. Sakamoto, Chem. Lett., 459 (1975).

20. K. Shirahama, Colloid and Polymer Sci., 252, 978 (1974).
21. H. Arai, M. Murata, and K. Shinoda, J. Colloid and Interface Sci., 37, 223 (1973).

22. M. N. Jones, ibid., 23, 36 (1967).

23. K. Martinek, A. P. Osipov, A. K. Yatsimirski, and I. V. Berzin, Tetrahedron, 31, 709 (1975).

24. T. Okubo and N. Ise, J. Org. Chem., 38, 3120 (1973).

25. T. Rudolfo, J. A. Hamilton, and E. H. Cordes, ibid., 39, 2281 (1974).

26. T. Kunitake, Y. Okahata, and T. Sakamoto, J. Am. Chem. Soc., 98, 7780 (1976).

27. J. A. Mollica, Jr., and K. A. Connors, ibid., 89, 308 (1967).

28. A. V. Hill, J. Physiol. (Proc. Physiol. Soc.), 40, iv (1910).

29. J-P. Changneux, Cold Spring Harbor Symp., 28, 497 (1963).

30. J. Monod, J-P. Changneux, and F. Jacob, $J$. Mol. Biol., 6, 306 (1963).

31. N. B. Madsen, Biochern. Biophys. Res. Commun., 15, 390 (1964).

32. Q. H. Gibson, Progr. Biophys. Biophys. Chem., 9, 1 (1961).

33. J. G. Gernhart and A. G. Pardee, J. Biol. Chem., 237, 891, (1962).

34. D. Piszkiewicz, J. Am. Chem. Soc., 98, 3053 (1976). 